Utah State University

DigitalCommons@USU

\title{
Multispectral Remote Sensing for Yield Estimation Using High- Resolution Imagery From an Unmanned Aerial Vehicle
}

\author{
Mahyar Aboutalebi \\ Utah State University, mahyar.aboutalebi@gmail.com \\ Alfonso F. Torres-Rua \\ Utah State University, alfonso.torres@usu.edu \\ Niel Allen \\ Utah State University, n.allen@usu.edu
}

Follow this and additional works at: https://digitalcommons.usu.edu/aggieair_pubs

Part of the Aviation Commons

\section{Recommended Citation}

Mahyar Aboutalebi, Alfonso F. Torres-Rua, and Niel Allen "Multispectral remote sensing for yield estimation using high-resolution imagery from an unmanned aerial vehicle", Proc. SPIE 10664, Autonomous Air and Ground Sensing Systems for Agricultural Optimization and Phenotyping III, 106640K (21 May 2018); http://dx.doi.org/10.1117/12.2305888

This Conference Paper is brought to you for free and open access by the AggieAir at DigitalCommons@USU. It has been accepted for inclusion in AggieAir Publications by an authorized administrator of DigitalCommons@USU. For more information, please contact digitalcommons@usu.edu.

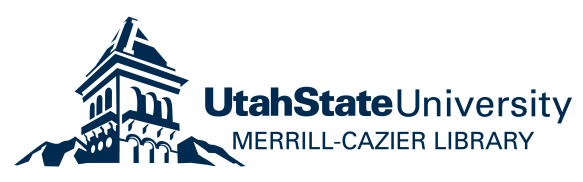




\section{Multispectral remote sensing for yield estimation using high-resolution imagery from an unmanned aerial vehicle}

Mahyar Aboutalebi, Alfonso F. Torres-Rua, Niel Allen

Mahyar Aboutalebi, Alfonso F. Torres-Rua, Niel Allen, "Multispectral remote sensing for yield estimation using high-resolution imagery from an unmanned aerial vehicle," Proc. SPIE 10664, Autonomous Air and Ground Sensing Systems for Agricultural Optimization and Phenotyping III, 106640K (21 May 2018); doi: $10.1117 / 12.2305888$

Event: SPIE Commercial + Scientific Sensing and Imaging, 2018, Orlando, Florida, United States 


\title{
Multispectral Remote Sensing for Yield Estimation Using High- Resolution Imagery from an Unmanned Aerial Vehicle
}

\author{
Mahyar Aboutalebi $^{* a}$, Alfonso F. Torres-Rua ${ }^{\mathrm{a}}$, Niel Allen ${ }^{\mathrm{a}}$ \\ Department of Civil and Environmental Engineering, Utah State University, Logan, USA
}

\begin{abstract}
Satellites and autonomous unmanned aerial vehicles (UAVs) are two major platforms for acquiring remotely-sensed information of the earth's surface. Due to the limitations of satellite-based imagery, such as coarse spatial resolution and fixed schedules, applications of UAVs as low-cost remote sensing systems are rapidly expanding in many research areas, particularly precision agriculture. UAVs can provide imagery with high spatial resolution (finer than 1 meter) and acquire information in visible, near infrared, and even thermal bands. In agriculture, vegetation characteristics such as health, water stress, and the amount of biomass, can be estimated using UAV imagery. In this study, three sets of high-resolution aerial imagery have been used for yield estimation based on vegetation indices. These images were captured by the Utah State University AggieAir ${ }^{\mathrm{TM}}$ UAV system flown in June 2017, August 2017, and October 2017 over a field experiment pasture site located in northern Utah. The pasture study area is primarily tall fescue. The field experiment includes 2050 x 20-m plots, with 4 replications of 5 irrigation levels. Approximately 60 yield samples were harvested after each flight. Sample locations were recorded with high-accuracy real-time kinematic (RTK) GPS. In addition, the leaf area index (LAI) for each sample plot was measured using an optical sensor (LAI2200C) before harvesting. The relationship of yield for each sample versus vegetation indices (VIs) was explored. The VIs include the normalized difference vegetation index (NDVI), calculated using AggieAir imagery, and LAI measured using a ground-based sensor. The results of this study reveal the correlation between vegetation indices and the amount of biomass.
\end{abstract}

Keywords: yield estimation $\cdot$ unmanned aerial vehicle $\cdot$ AggieAir $\cdot$ vegetation indices $\cdot$ NDVI $\cdot$ LAI

\section{INTRODUCTION}

The traditional approach to yield estimation is built on the farmer's knowledge and a destructive sampling procedure. Commonly, this approach has been limited to simple surveys based on crop-cutting experiments and multiplying the yield estimate by the crop acreage, which is extremely laborious and expensive. With the emergence of satellites, advances in unmanned aerial vehicle (UAV) technology, and the evolving integration of remotely sensed data into biophysical modeling, considerable attention has been given to determining the relationship between yield and the spectral data, focusing on yield model development. Remotely sensed data enable us to map productivity over a small, large, or even global view in a cost-efficient manner. Although many factors such as soil type, plant type, and weather situation affect yield, the general assumption in estimating yield from remotely sensed data is that the concentration of biomass can be determined from changes in the spectral response. Thus, the correlation between yield at near-heading stage and reflectance from the crop and canopy parameters can be used to develop remote sensing yield models. However, a comprehensive assessment of these types of relationships requires a large number of crop samples, especially for heterogeneous areas. 
Although many studies have been conducted to quantify the relationship between remotely-sensed data and yield in various parts of the world, achieving efficient and accessible yield estimators from satellite or high-resolution UAV imagery is still an ongoing investigation. One possibility for improving yield models entails using high-resolution imagery along with crop height and canopy structure data derived from UAV 3D imagery (point cloud). Previous studies have used a combination of both canopy geometry information and high-resolution spatial data to enhance yield models (Geipel et al. 2014 [6] and Bending et al 2013[4]).

Visible reflectance from a crop canopy is low because of the absorption of visible light by pigments for photosynthesis, while NIR reflectance is high due to the cellular surface in the leaf mesophyll tissues (Song et al. 2013[14]). These two parts of the electromagnetic spectrum subsequently attract the attention of researchers as they seek to develop numerous VIs and link them to crop productivity (Tucker and Sellers 1986 [15]). For example, Pinar and Curran (1996) [10] found a strong correlation between red-edge channel and both chlorophyll content $(\mathrm{r}=0.93)$ and chlorophyll concentration $(\mathrm{r}=0.86)$. Among all possible VIs, many studies have shown the relationship between crop yield and vegetation indices such as Normalized Difference Vegetation Index (NDVI), derived from the visible and near-infrared bands, and also Leaf Area Index (LAI).

Goward et al. (1985) [7] showed that NDVI derived from Advanced Very High Resolution Radiometer (AVHRR) is highly correlated with net primary productivity (NPP). Singh and Goyal (1992) [12] and Singh et al (1993) [13] addressed idea that the characteristics of healthy vegetation can be identified based on the spectral responses at different bands of the electromagnetic spectrum. They developed a linear regression yield model based on NDVI and Ratio Vegetation index (RVI) from Landsat Thematic Mapper (TM) data and showed that NDVI is a more efficient estimator in the yield model as compared to RVI. Hashimoto et al. (2012) [8] tested four VIs from Moderate Resolution Imaging Spectroradiometer (MODIS) for gross primary production (GPP), including NDVI, LAI, Enhanced Vegetation Index (EVI), and Fraction of Photosynthetically Active Radiation (FPAR). The results indicated that each of these VIs can represent 50-80\% of GPP variability. Aside from these, numerous studies have provide experimental validation of the theory that VIs derived from satellite data correlate well with vegetation productivity (Bella et al. 2004 [3]; Jianlong et al. 1998 [9]).

Although the results are encouraging and we can conclude that VIs representing canopy characteristics, particularly chlorophyll content, are correlated to the amount of biomass and productivity, a critical challenge in the use of VIs for identifying the vegetation status is to minimize the impact of external factors that occur mostly in the coarse scale. Since each pixel at the low-resolution imagery scale contains a mixture of information from soil and crops together, the linear or nonlinear relationship seems to be valid at that specific resolution. This mixture of information can lead to underestimation of the yield due to aggregation of non-photosynthetic material such as soil with the spectral data of the crops. The present study aimed to evaluate the correlation of yield with each of the spectral bands, VIs, canopy geometry information derived from 3D UAV imagery, and in situ measurements of LAI. The results of this study reveal the type of trend line that is more fitted to the relationship between yield and dependent variables along with the amount of correlation between them. Moreover, this study examines whether the information derived from 3D UAV imagery such as crop height can be an efficient estimator for yield models.

\subsection{Study Area}

\section{METHODS}

This investigation to derive the correlation between possible estimators and crop yield was conducted in a Utah State University field experiment pasture site located in northern Utah. The pasture study area contained primarily tall fescue. The field experiment included $2050 \times 20 \mathrm{~m}$ plots, with 4 replications of 5 irrigation levels (Fig 1). Fig 1 shows the study area along with the 5 irrigation levels. The values of $0,1,2,3$, and 4 in Fig 1 mean no irrigation, one irrigation, two irrigations, three irrigations, and most irrigations, respectively. In Fig 1, CSM indicates the location of soil moisture sensors installed in the experimental field. 


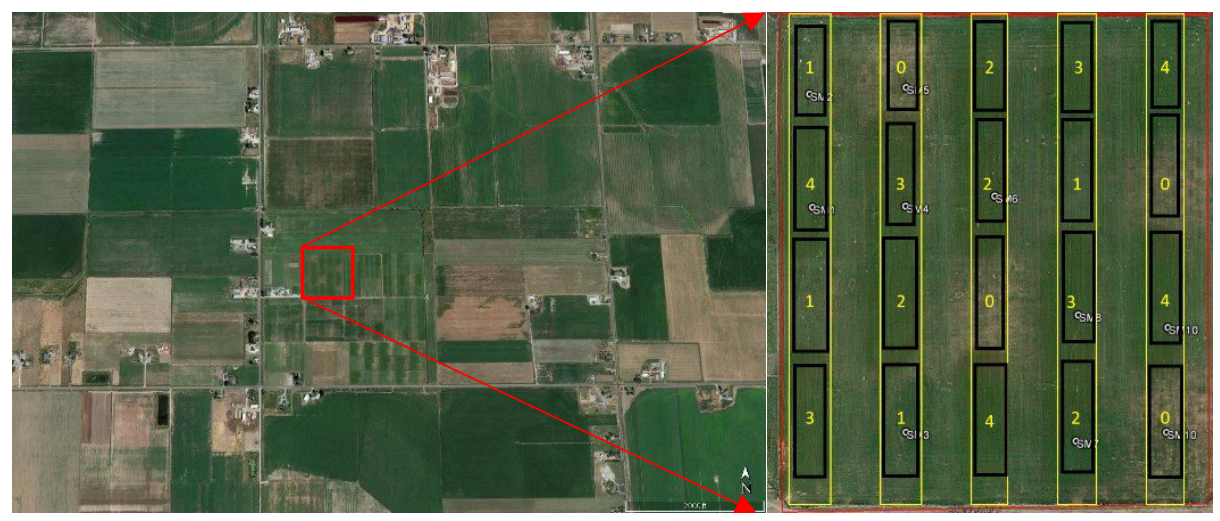

Fig 1. A layout of the study area along with a map of the 5 irrigation levels

\subsection{Data}

\subsubsection{High-Resolution Imagery from AggieAir UAV, GPS and LAI}

Three sets of high-resolution imagery were acquired over the experimental field (on June 16, August 22, and October 17, 2017) using UAVs developed by the AggieAir team at USU. All of the images have 5 bands: Red, Green, Blue, nearinfrared (NIR), and Thermal. Also, the point cloud of each image was provided by the AggieAir team. The elevation of the first two flights was $400 \mathrm{~m}$ above the ground, and the images were captured using a fixed wing UAV (Fig 2.a). The elevation of last flight was $120 \mathrm{~m}$, and the images were captured using a multirotor vertical take-off and landing (VTOL) UAV (Fig 2.b). For all flights, LAI was measured with a LAI-2200C sensor, elevation of ground control points was collected using high-accuracy real-time kinematic (RTK) GPS, and finally, the height of the sampled canopy before and after harvesting were recorded using a leveling rod. Image resolution was $0.1 \mathrm{~m}$ for the first and second flights and $0.02 \mathrm{~m}$ for the last flight. 


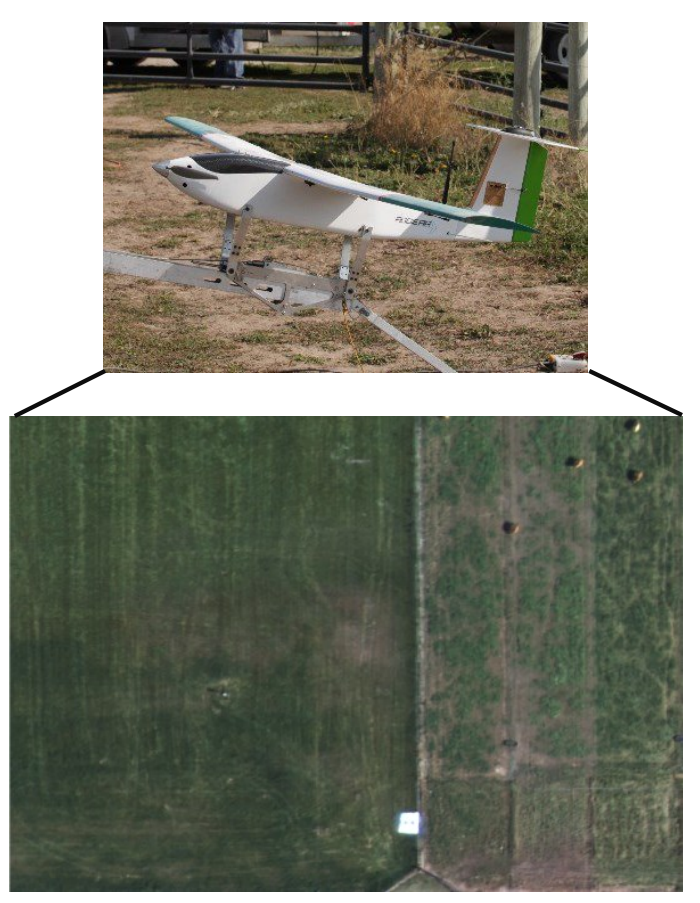

(a)

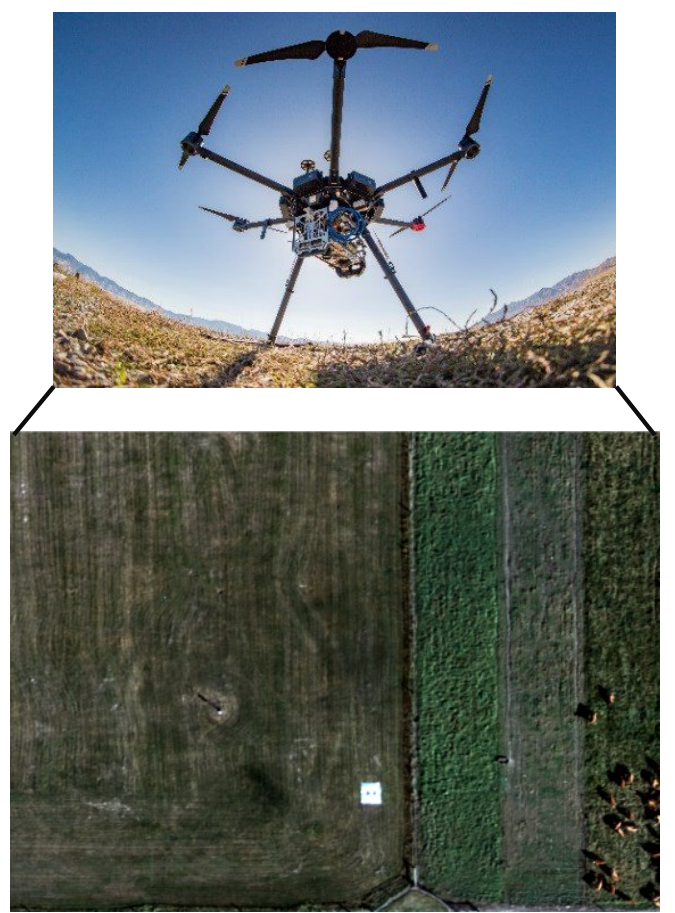

(b)

Fig 2. Sample aerial imagery captured by AggieAir UAV at $10 \mathrm{~cm}$ resolution (a) and by the VTOL at $2 \mathrm{~cm}$ resolution (b)

\subsubsection{Yield}

Approximately 60 yield samples were harvested after each flight. The crop within each plot was generally homogeneous in terms of the crop height and the crop yield. Wet and dry weights of samples were measured and the yield was calculated using Eq.1,

$$
Y=\frac{S_{w} *\left(1-S_{m}\right)}{S_{\text {area }}}
$$

in which $Y=$ yield (Tons/Acre), $S_{w}=$ sample weight (Tons), $S_{m}=$ sample moisture, and $S_{\text {area }}=$ the area of the harvested sample (Acres).

\subsubsection{DTM and DSM}

To estimate some of the canopy geometry parameters such as canopy volume or canopy height, we subtracted the Digital Terrain Model (DTM) from the Digital Surface Model (DSM). The DTM was obtained from the UAV point cloud. To generate the DSM raster layer, the geometry information (latitude, longitude, and altitude) for about 500 points was collected using RTK GPS and converted to a raster file using the Kriging interpolation method. Fig 3 shows the DSM and DTM maps of the experimental field. 


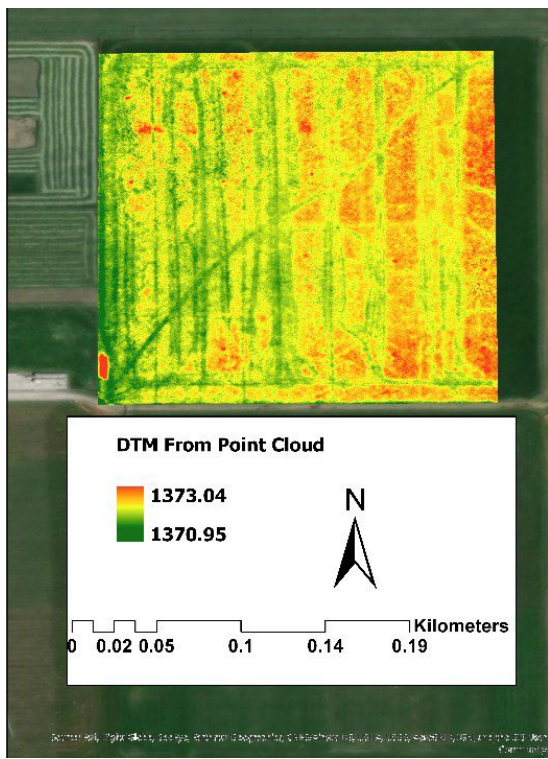

(a)

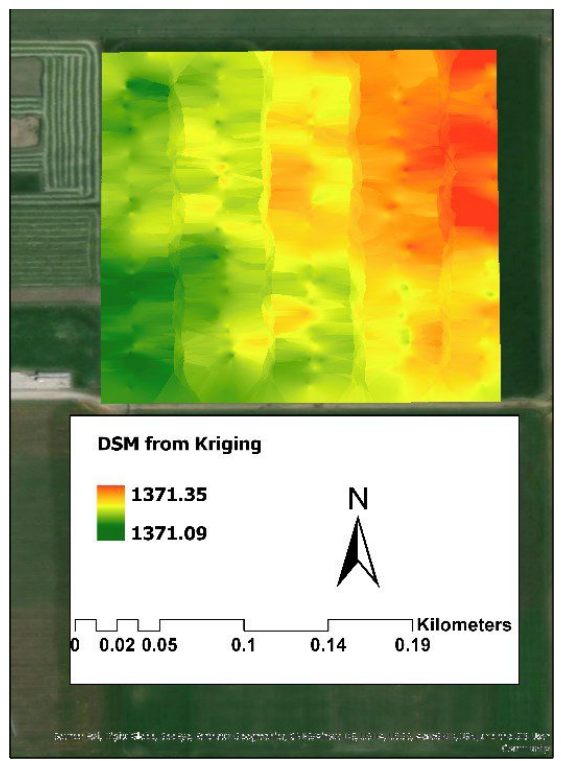

(b)

Fig 3. DTM from point cloud for June (a), DSM generated from 500 GPS points and the Kriging method (b)

As shown in Fig 3, the elevation of both DTM and DSM increases from the southwest side to the northeast side. The changes in elevation obtained from the June flight were about $3 \mathrm{~m}$ for the DTM and $25 \mathrm{~cm}$ for the DSM.

\subsection{Methodology}

The process of the investigation is shown in Fig 4.

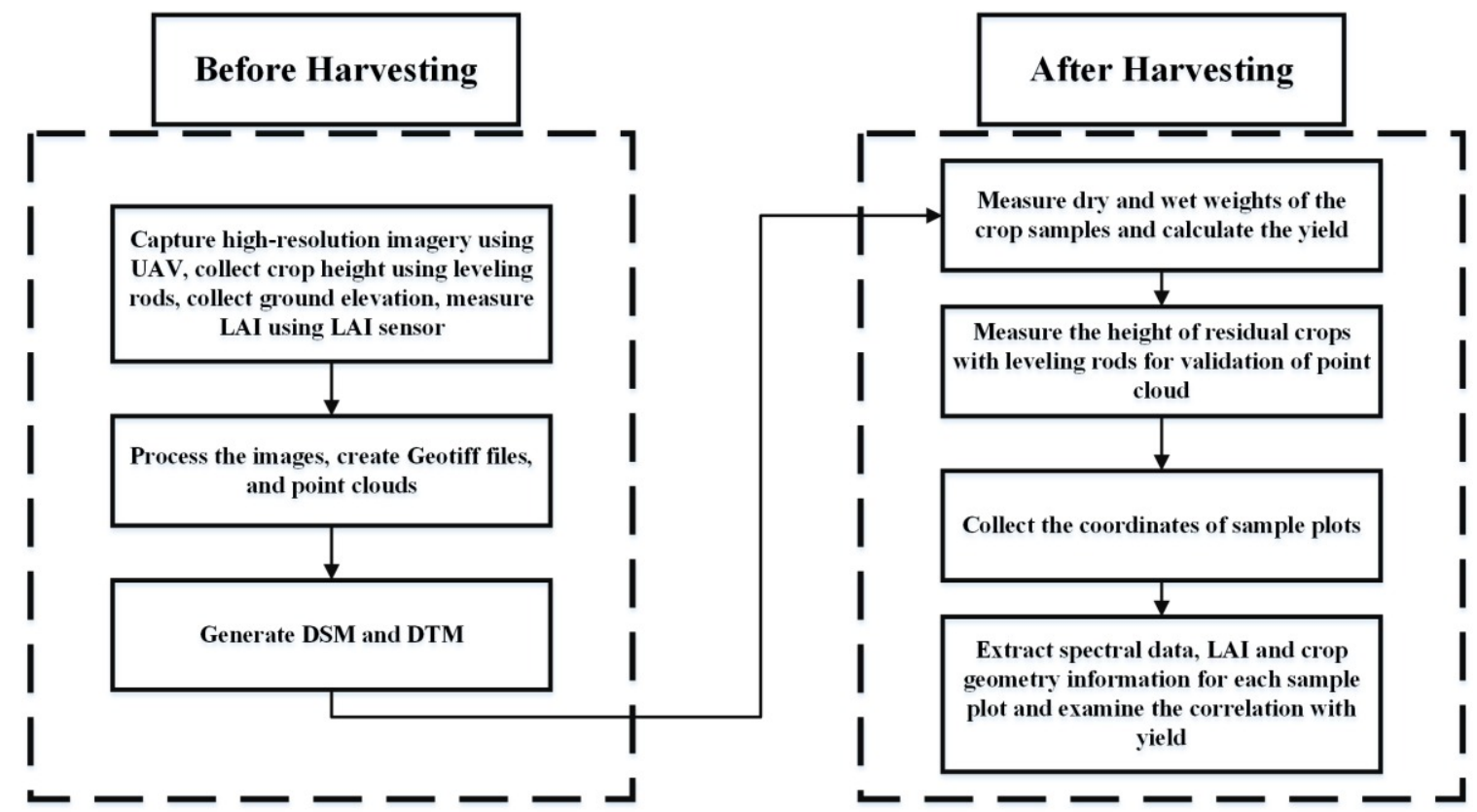

Fig 4. A flowchart illustrating the process of the study 
As shown in Fig 4, high-resolution imagery, crop height, LAI, and ground elevation were collected before harvesting. This was followed by a two-step image processing phase that included (1) radiometric calibration for converting the digital images to a measure of reflectance and (2) image mosaicking and orthorectification using AgiSoft software [1] for combining all images into one large mosaic image and creating a point cloud dataset. A further discussion about image pre-processing and a sensor description are provided by Elarab et al. (2015) [5]. Based on the point cloud datasets and the ground elevation, respectively, DTM and DSM were created. The DTM and DSM were generated using the "Point to Raster" and "Kriging" toolbox from ArcGIS pro software, respectively. The differences between DTM and DSM show an estimate of crop height for each pixel. After harvesting, the yield of grass harvested was calculated for each sample based on Eq.1. The height of the residual crop was measured by the leveling rod. The measurements of crop height before and after harvesting were used to validate the crop height estimated from DTM and DSM. The coordinate of each sample plot was recorded by RTK GPS, and the average of spectral data, VIs, crop height, and LAI provided by the UAV and the LAI sensors was extracted for each of the sample plots. Ultimately, the relationship and correlation between the yield of each sample and those parameters was evaluated.

\section{RESULTS and DISCUSSION}

\subsection{Correlation between the yield and spectral data, VIs, crop height, and LAI}

The possibility of estimating crop yield from the reflectance of each multispectral band, NDVI, RVI, LAI and crop height has been investigated in this study. The scatter plot for each of the possible estimators and the yield obtained from sample plots based on crop cutting experiments in July (first harvesting), August (second harvesting), and October (third harvesting) are shown in Fig 5. For each correlation, 5 different of trend-line types (exponential, linear, logarithmic, polynomial and power) are tested. The best accuracy in terms of trend line and determination of coefficient are summarized in Table 1.

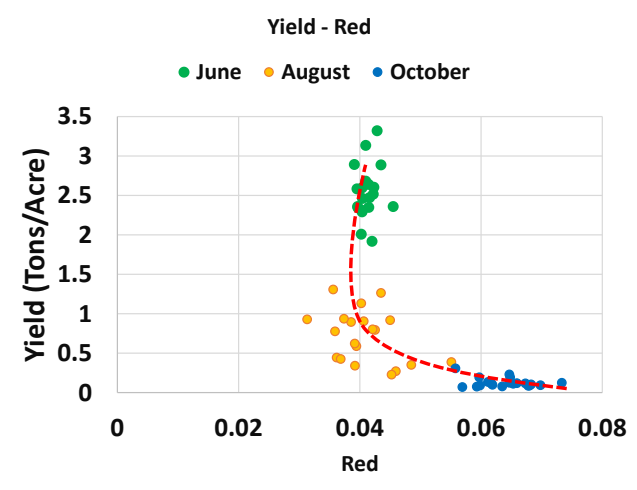

(a)

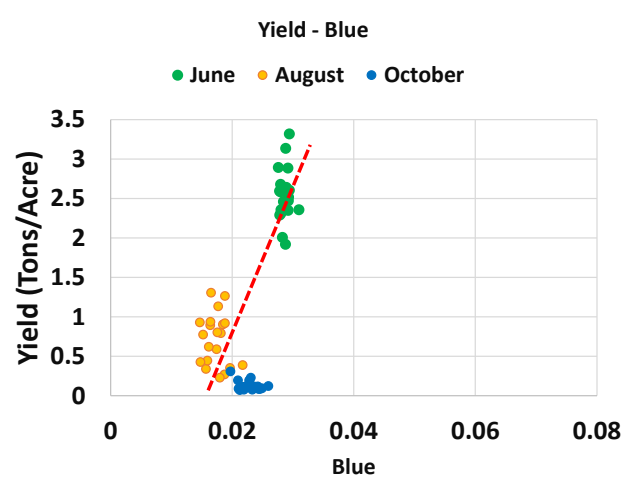

(b) 


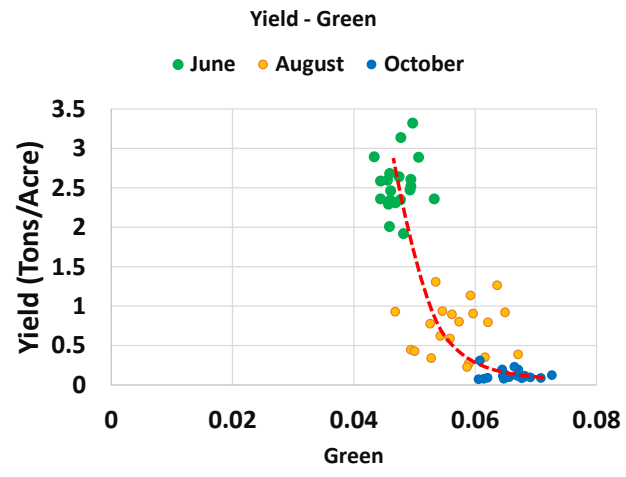

(c)

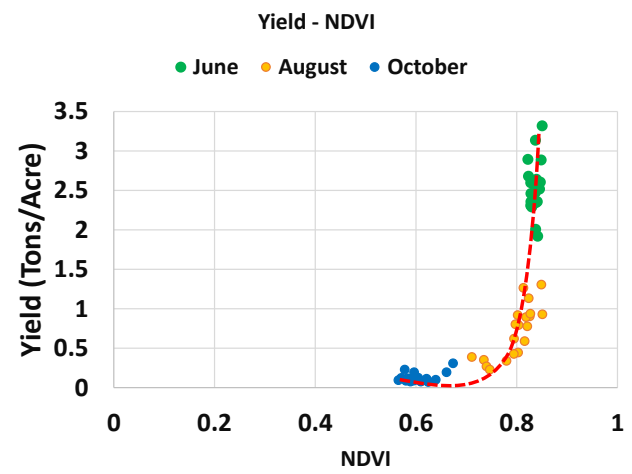

(e)

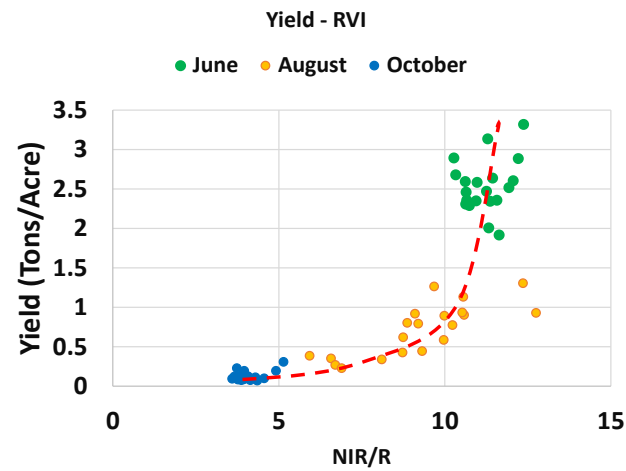

(g)

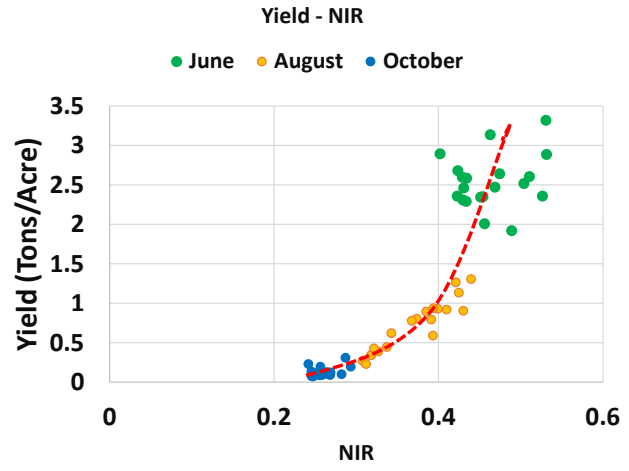

(d)

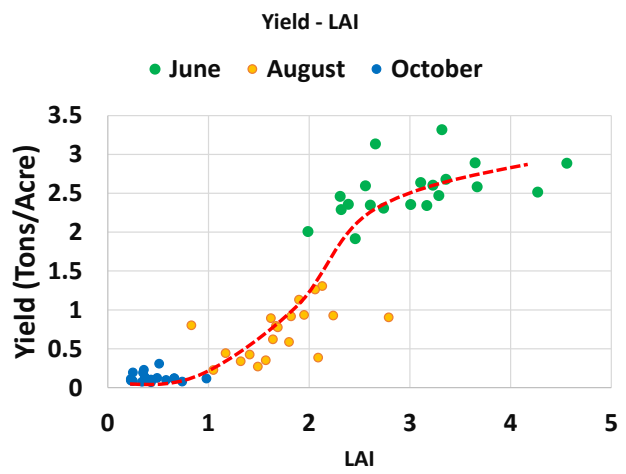

(f)

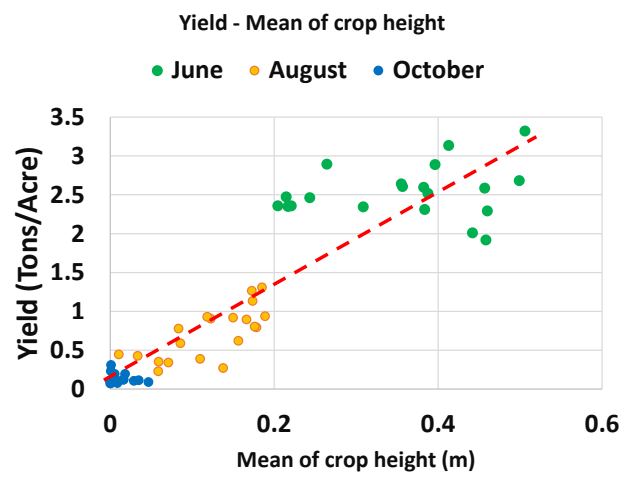

(h)

Fig 5. The scatter plot for each of the possible estimators and the yield 
Table 1 . The best trend-line type fitted between yield and the possible estimators based on determination of coefficient

\begin{tabular}{ccc}
\hline Name & Trendline type & Determination of coefficient \\
\hline Yield-Red & Exponential & 0.687 \\
\hline Yield-Blue & Linear & 0.450 \\
\hline Yield-Green & Exponential & 0.734 \\
\hline Yield-NIR & Power & $\mathbf{0 . 9 2 0}$ \\
\hline Yield-NDVI & Power & $\mathbf{0 . 8 4 7}$ \\
\hline Yield-LAI & Polynomial & $\mathbf{0 . 8 6 9}$ \\
\hline Yield-RVI & Exponential & $\mathbf{0 . 8 9 7}$ \\
\hline Yield-Mean of crop height & Linear & $\mathbf{0 . 8 4 0}$ \\
\hline
\end{tabular}

Fig 5 shows that most of the possible estimators are directly correlated to the yield. The inverse relationship between Red bands and yield is due to the chlorophyll content in the leaves. Chlorophyll content absorbs energy in the red band. Because the biomass and, particularly, the chlorophyll concentration were higher in June (first harvesting) than August and higher in August than October (last cutting), the reflectance of the Red band was at a minimum in June and was higher in October.

As is evident in Fig 5 and Table 1, all possible estimators can be related to the yield with a non-linear function except for Blue and the mean of crop height. Results indicate that all VIs are significantly related to the yield and that RVI is a bit more correlated to the crop yield than NDVI and LAI. Among the spectral bands, NIR, Green, and Red are more correlated to the yield, respectively, than Blue. However, the correlation between the yield and each of the single bands in the optical wavelength is not as high as for VIs. Among each of spectral bands, the poorest correlation is related to the Blue band and the highest is for NIR. Thus, we can conclude that the reflectance information from each of optical bands individually cannot be an efficient estimator for the yield models.

One of the most important observations from these graphs is related to the saturation situation that occurs within the relationship between VIs and yield for well-developed canopies. As illustrated in Fig 5, it is evident that the slope of the trend lines for the standard VIs whose upper bound is fixed to 1 is approaching infinity (in June), which means that increasing the yield cannot lead to a significant increase in the VIs. Also, comparing the graphs of Yield-NDVI and YieldLAI reveals that NDVI is saturated for LAI $>2.5$, in agreement with the investigations conducted by Serrano et al. 2000 [11] and Asrar et al. 1984 [2]. In contrast, LAI and crop height have a potential to be good estimators in a dense situation. Therefore, the use of NDVI and RVI in the yield models is limited to the initial stage of growth when LAI is low. 


\section{CONCLUISON}

In this study, the correlation and relationship between the yield of a pasture in the USU experimental field and spectral information from multispectral bands, VIs (NDVI, RVI, and LAI), and the crop height estimated from 3D high-resolution UAV imagery are evaluated. Results indicated that the variation in crop yield is clearly translated into spectral data, VIs, and crop height. The linear relationship of the yield versus Blue and crop height is only a best fitting function. However, VIs and other parameters are non-linearly related to the yield. Among all VIs, RVI was more correlated $\left(\mathrm{R}^{2}=89.7 \%\right)$ to the yield, although the other VIs also showed a significant correlation with the yield: NDVI $\left(\mathrm{R}^{2}=84.7 \%\right)$ and $\mathrm{LAI}\left(\mathrm{R}^{2}=86.9 \%\right)$. Among the individual bands, NIR $\left(\mathrm{R}^{2}=92 \%\right)$ had the strongest relationship with yield. The correlation of the crop height was comparable to the VIs and was about $84 \%$ in terms of the determination of coefficient. Results showed that NDVI and RVI will be saturated for the LAI $>2.5$ and thus cannot be efficient estimators when the canopy is well-developed. For this reason they are recommended to be used in yield models only for the initial stage of growth.

\section{ACKNOWLEDGEMENT}

This project was financially supported by the Utah State University Extension Water Conservation Initiative Funding and by the Utah Water Research Laboratory at Utah State University. The authors wish to thank the AggieAir UAV Remote Sensing Group at the Utah Water Research Laboratory for their UAV technology and skill and hard work in acquiring the scientific quality, high-resolution aerial imagery used in this project.

\section{REFERENCES}

[1] AgiSoft, L. L. C., and Russia St Petersburg. "Agisoft photoscan." Professional Edition (2016).

[2] Asrar, G., M. Fuchs, E.T. Kanemasu, and J.L. Hatfield. "Estimating absorbed photosynthetic radiation and leaf area index from spectral reflectance in wheat". Agronomy Journal. 76:300-306 (1984).

[3] Bella, D., Faivre, R., Ruget, F., Seguin, B., Guérif, M., Combal, B., Weiss, M., and Rebella, C. "Remote sensing capabilities to estimate pasture production in France", International Journal of Remote Sensing, 25:23, 53595372, (2004).

[4] Bendig, J., Willkomm, M., Tilly, N., Gnyp, M.L., Bennertz, S., Qiang, C., Miao, Y., Lenz-Wiedemann, V.I.S., and Bareth, G. "Very high resolution crop surface models (CSMs) from UAV-based stereo images for rice growth monitoring in Northeast China". International Archives of the Photogrammetry, Remote Sensing and Spatial Information Sciences, 40, 45-50 (2013).

[5] Elarab, M., Ticlavilca, A.M., Torres-Rua, A.F., Maslova, I., and McKee, M. "Estimating chlorophyll with thermal and broadband multispectral high resolution imagery from an unmanned aerial system using relevance vector machines for precision agriculture. International Journal of Applied Earth Observation and Geoinformation. 43, 32-42 (2015).

[6] Geipel, J., Link, J., and Claupein, W. "Combined spectral and spatial modeling of corn yield based on aerial images and crop surface models acquired with an unmanned aircraft system". Remote Sensing, 6, 10335-10355, (2014).

[7] Goward, S.N., Tucker, C.J., and Dye, D.G. "North American vegetation patterns observed with the NOAA-7 advanced very high resolution radiometer". Plant Ecology, 64(1), 3-14 (1985).

[8] Hashimoto, H., Wang, W., Milesi, C, et al. "Exploring simple algorithms for estimating gross primary production in forested areas from satellite data", Remote Sensing, 4, 303-326 (2012).

[9] Jianlong, L., Tiangang, L. and Quangong, C. "Estimating grassland yields using remote sensing and GIS technologies in China, New Zealand", Journal of Agricultural Research, 41, 31-38, (1998).

[10] Pinar, A., Curran, P.J. "Technical Note Grass chlorophyll and the reflectance red edge", Intentional Journal of Remote Sensing, 17, 351-7 (1996).

[11] Serrano, L., Filella, I., and Penuelas, J. "Remote sensing of biomass and yield of winter wheat under different nitrogen supplies". Crop Science, 40, 723 - 731 (2000). 
[12] Singh, R., and Goyal, R. C. "Use of remote sensing technology in crop yield estimation surveys", Project report, IASRI, New Delhi (1993).

[13] Singh, R., Goyal, R. C., Saha, S. K. and Chhikara, R. S. "Use of satellite spectral data in crop yield estimation surveys", International Journal of Remote Sensing, 13, 2583-2592 (1992).

[14] Song, C., Dannenberg, M.P., and Hwang, T. "Optical remote sensing of terrestrial ecosystem primary productivity", Progress in Physical Geography, 37, 834-54 (2013).

[15] Tucker, C.J., and Sellers, P.J. "Satellite remote sensing of primary production", International Journal of Remote Sensing, 7(11), 1395-1416 (1986). 